University of Nebraska - Lincoln

DigitalCommons@University of Nebraska - Lincoln

2010

Fractionation of oxygen isotopes in phosphate during its interactions with iron oxides

Deb P. Jaisi

Yale University, deb.jaisi@yale.edu

Ruth E. Blake

Yale University

Ravi K. Kukkadapu

Pacific Northwest National Laboratory, ravi.kukkadapu@pnl.gov

Follow this and additional works at: https://digitalcommons.unl.edu/usdoepub

Part of the Bioresource and Agricultural Engineering Commons

Jaisi, Deb P.; Blake, Ruth E.; and Kukkadapu, Ravi K., "Fractionation of oxygen isotopes in phosphate during its interactions with iron oxides" (2010). US Department of Energy Publications. 164.

https://digitalcommons.unl.edu/usdoepub/164

This Article is brought to you for free and open access by the U.S. Department of Energy at DigitalCommons@University of Nebraska - Lincoln. It has been accepted for inclusion in US Department of Energy Publications by an authorized administrator of DigitalCommons@University of Nebraska - Lincoln. 


\title{
Fractionation of oxygen isotopes in phosphate during its interactions with iron oxides
}

\author{
Deb P. Jaisi ${ }^{\mathrm{a}, *}$, Ruth E. Blake ${ }^{\mathrm{a}}$, Ravi K. Kukkadapu ${ }^{\mathrm{b}}$ \\ ${ }^{a}$ Department of Geology and Geophysics, Yale University, P.O. Box 208109, New Haven, CT 06520, USA \\ ${ }^{\mathrm{b}}$ Pacific National Northwest Laboratory, Richland, WA 99352, USA
}

Received 11 February 2009; accepted in revised form 9 November 2009; available online 14 November 2009

\begin{abstract}
Iron (III) oxides are ubiquitous in near-surface soils and sediments and interact strongly with dissolved phosphates via sorption, co-precipitation, mineral transformation and redox-cycling reactions. Iron oxide phases are thus, an important reservoir for dissolved phosphate, and phosphate bound to iron oxides may reflect dissolved phosphate sources as well as carry a history of the biogeochemical cycling of phosphorus $(\mathrm{P})$. It has recently been demonstrated that dissolved inorganic phosphate (DIP) in rivers, lakes, estuaries and the open ocean can be used to distinguish different $\mathrm{P}$ sources and biological reaction pathways in the ratio of ${ }^{18} \mathrm{O} /{ }^{16} \mathrm{O}\left(\delta^{18} \mathrm{O}_{\mathrm{P}}\right)$ in $\mathrm{PO}_{4}{ }^{3-}$. Here we present results of experimental studies aimed at determining whether non-biological interactions between dissolved inorganic phosphate and solid iron oxides involve fractionation of oxygen isotopes in $\mathrm{PO}_{4}$. Determination of such fractionations is critical to any interpretation of $\delta^{18} \mathrm{O}_{\mathrm{P}}$ values of modern (e.g., hydrothermal iron oxide deposits, marine sediments, soils, groundwater systems) to ancient and extraterrestrial samples (e.g., BIF's, Martian soils). Batch sorption experiments were performed using varied concentrations of synthetic ferrihydrite and isotopically-labeled dissolved ortho-phosphate at temperatures ranging from 4 to $95{ }^{\circ} \mathrm{C}$. Mineral transformations and morphological changes were determined by X-Ray, Mössbauer spectroscopy and SEM image analyses.

Our results show that isotopic fractionation between sorbed and aqueous phosphate occurs during the early phase of sorption with isotopically-light phosphate $\left(\mathrm{P}^{16} \mathrm{O}_{4}\right)$ preferentially incorporated into sorbed/solid phases. This fractionation showed negligible temperature-dependence and gradually decreased as a result of O-isotope exchange between sorbed and aqueousphase phosphate, to become insignificant at greater than $\sim 100 \mathrm{~h}$ of reaction. In high-temperature experiments, this exchange was very rapid resulting in negligible fractionation between sorbed and aqueous-phase phosphate at much shorter reaction times. Mineral transformation resulted in initial preferential desorption/loss of light phosphate $\left(\mathrm{P}^{16} \mathrm{O}_{4}\right)$ to solution. However, the continual exchange between sorbed and aqueous $\mathrm{PO}_{4}$, concomitant with this mineralogical transformation resulted again in negligible fractionation between aqueous and sorbed $\mathrm{PO}_{4}$ at long reaction times $(>2000 \mathrm{~h})$. This finding is consistent with results obtained from natural marine samples. Therefore, ${ }^{18} \mathrm{O}$ values of dissolved phosphate (DIP) in sea water may be preserved during its sorption to iron-oxide minerals such as hydrothermal plume particles, making marine iron oxides a potential new proxy for dissolved phosphate in the oceans.
\end{abstract}

(c) 2009 Elsevier Ltd. All rights reserved.

\section{INTRODUCTION}

In sediments and soils under Earth surface conditions, iron $(\mathrm{Fe})$ occurs predominantly as $\mathrm{Fe}^{3+}$ in the form of spar-

\footnotetext{
* Corresponding author. Tel.: +1 203432 3180; fax: +1 2034323134.

E-mail address: deb.jaisi@yale.edu (D.P. Jaisi).
}

ingly soluble Fe-oxide minerals such as ferrihydrite, goethite, and hematite (Cornell and Schwertmann, 2003). Phosphate interacts strongly with Fe-oxides (includes hydroxides and oxyhydroxides) via to Fe-oxide surfaces (Paige et al., 1997; Borch et al., 2007). Phosphate can also co-precipitate with or become occluded within newly forming and transformed $\mathrm{Fe}$-oxide minerals and even influence the type of Fe-oxide formed (e.g., lepidocrocite vs.

0016-7037/\$ - see front matter (c) 2009 Elsevier Ltd. All rights reserved. doi:10.1016/j.gca.2009.11.010 
maghemite) depending on the solution $\mathrm{pH}$, temperature and $\mathrm{P} / \mathrm{Fe}$ ratio (Galvez et al., 1999; Torrent and Barron, 2000). The sorption of dissolved inorganic ortho-phosphate, $\mathrm{PO}_{4}$, to Fe-oxide-rich sediments can reduce the concentration of bio-available $\mathrm{P}$ and buffer dissolved $\mathrm{PO}_{4}$ to growth-limiting concentrations (Blake et al., 2001). For example, Fe-oxides formed in association with hydrothermal vent fluids at mid-ocean ridge (MOR) systems are a major sink in the global P cycle (Berner, 1973; Wheat et al., 1996). Other forms of hydrothermal iron oxides that scavenge phosphate include particulates in venting fluids, crusts formed by weathering of iron-rich basalts and Fe-sulfides, and microbial mats formed by Fe-oxidizing bacteria (FeOB) associated with low-temperature diffuse-flow venting (Wheat et al., 1996; Emerson and Moyer, 2002).

In aquatic systems, the ${ }^{18} \mathrm{O}:{ }^{16} \mathrm{O}$ ratio of dissolved orthophosphate, $\left(\mathrm{PO}_{4}\right)_{\mathrm{aq}}$, has recently been shown to record the effects of specific processes and reactions occurring during the biogeochemical cycling of $\mathrm{P}$, making phosphate oxygen isotope compositions (i.e., $\delta^{18} \mathrm{O}_{\mathrm{p}}$ values) a useful tool for investigating $\mathrm{P}$ cycling pathways in aquatic systems including rivers, lakes, estuaries and the open ocean (Markel et al., 1994; Blake et al., 1997, 2005; Colman et al., 2005; McLaughlin et al., 2006). In biologically-mediated reactions, oxygen isotope exchange between $\left(\mathrm{PO}_{4}\right)_{\mathrm{aq}}$ and $\mathrm{H}_{2} \mathrm{O}$ is very rapid due to enzymatic catalysis (Luz and Kolodny, 1985; Blake et al., 1997, 2005; Paytan et al., 2002). Under abiotic conditions and at most earth-surface temperatures $\left(<80^{\circ} \mathrm{C}\right)$ and pressures, however, phosphate resists O-isotope exchange with water (Tudge, 1960; Blake et al., 1997, 1998; Lecuyer et al., 1999). Therefore, in fully abiotic systems, O-isotope fractionation between aqueous and solid phase phosphate should reflect the combined isotope effects due to exchange between aqueous $\left[\left(\mathrm{PO}_{4}\right)_{\mathrm{aq}}\right]$ and sorbed $\left[\left(\mathrm{PO}_{4}\right)_{\text {srb }}\right]$ phosphate (e.g., Slomp et al. (1998) and references therein) at temperatures $<80^{\circ} \mathrm{C}$. Iron oxides from low-temperature hydrothermal systems at the EPR and Larson's Seamounts have been shown to contain $\mathrm{PO}_{4}$ with a strong biological signature, consistent with cellular turnover/metabolism of sorbed $\mathrm{PO}_{4}$ at the ambient vent temperature (Blake et al., 2001). In environments such as the Loihi Seamount where both abiogenic and biogenic iron oxides may form side-by-side, the isotopic signature of sorbed or co-precipitated phosphate may reflect different signatures in different iron oxide microlayers.

Several (bio)geochemical processes and reaction networks associated with phosphorus cycling in aquatic environments (Fig. 1 in Blake et al., 2005) affect both the concentration and isotopic composition of phosphates. It remains to be determined, however, if cycling of phosphate during both biotic and abiotic phosphate-iron oxide interactions - a dominant process in marine sediments and soils - involves fractionations of oxygen isotopes. In fact, knowledge of factors affecting O-isotope exchange rates and fractionation between sorbed and aqueous-phase phosphates, if any, is essential to interpretation of both aqueous and solids-phase phosphate $\mathrm{O}$-isotope ratios measured in any natural system where iron oxides occur, such as hydrothermal vents, soils, banded iron formations and iron-rich soils/deposits on Mars. Characterization of this important pathway in the biogeochemical cycling of phosphate (Fig. 1 in Blake et al., 2005) is also crucial to distinguishing $\delta^{18} \mathrm{O}_{\mathrm{p}}$ signatures produced by biotic vs. abiotic processes.

Research presented here is focused primarily on the determination of the fractionations of oxygen isotopes in phosphates during abiotic sorption/desorption to/from ferrihydrite under conditions relevant to ocean settings. Since the transformation of ferrihydrite to other more stable minerals may affect partitioning of phosphate, we quantified this transformation using Mössbauer spectroscopy. Our results show that the sorption/desorption process involves initial kinetic fractionation of oxygen isotopes, however, at long reaction times ( $>100 \mathrm{~h}$ at room temperature), isotopic exchange between sorbed and aqueous-phase phosphates results in no measurable O-isotope fractionation between these phases.

\section{MATERIALS AND METHODS}

\subsection{Synthesis and purification of ferrihydrite}

Ferrihydrite was synthesized from ferric nitrate using the method of Cornell and Schwertmann (2003). Briefly, $1 \mathrm{M}$ $\mathrm{KOH}$ was slowly added to a solution of $0.1 \mathrm{M}$ $\mathrm{Fe}\left(\mathrm{NO}_{3}\right)_{3} \cdot 9 \mathrm{H}_{2} \mathrm{O}$ while stirring, until the $\mathrm{pH}$ reached 7.5. Once $\mathrm{pH}$ was stabilized, the ferrihydrite precipitate was washed three times by centrifugation using deionized water. The ferrihydrite was then dialyzed using deionized water for 10 days to remove electrolytes. To avoid any possible subsequent changes in ferrihydrite properties, the dialyzed samples were used immediately in experiments. One portion of each sample was oven dried for density measurement and another portion was freeze dried and used to characterize mineralogical and textural properties using standard powder XRD, Mössbauer spectroscopy and SEM image analyses.

\subsection{Phosphate sorption experiments}

Phosphate sorption experiments were performed to determine equilibrium distribution between aqueous and solid phase phosphate as a function of ferrihydrite and phosphate concentration. Three series of experiments were carried out to determine the $\mathrm{O}$-isotopic fractionation between solid and aqueous-phase phosphate (Table 1). The first series of experiments was conducted with a ferrihydrite concentration of $10 \mathrm{~g} / \mathrm{L}$ and $78 \mathrm{mM}$ of ${ }^{18} \mathrm{O}$-labeled phosphate $(12.7 \%$ o VSMOW) in a $1600 \mathrm{~mL}$ reaction volume at four different temperatures $\left(4,21,70\right.$ and $\left.95^{\circ} \mathrm{C}\right)$. The high concentration of $\mathrm{PO}_{4}$ was required to maintain almost equal distribution of $\mathrm{PO}_{4}$ in sorbed and aqueous phases, as well as to allow extraction of several sample aliquots to understand the mechanism of sorption/desorption and associated isotopic fractionations. The second series of experiments was performed to understand the effect of the mass of ferrihydrite present [by using $0.5 \mathrm{~g} / \mathrm{L}$ ferrrihydrite and $2.5 \mathrm{mM}{ }^{18} \mathrm{O}$-labeled phosphate $(33.9 \%$ ) $]$ in a $500 \mathrm{~mL}$ reaction volume at two temperatures $\left(21\right.$ and $\left.70{ }^{\circ} \mathrm{C}\right)$. Both sets of experiments were performed at $\mathrm{pH} 8.2( \pm 0.2)$ in 

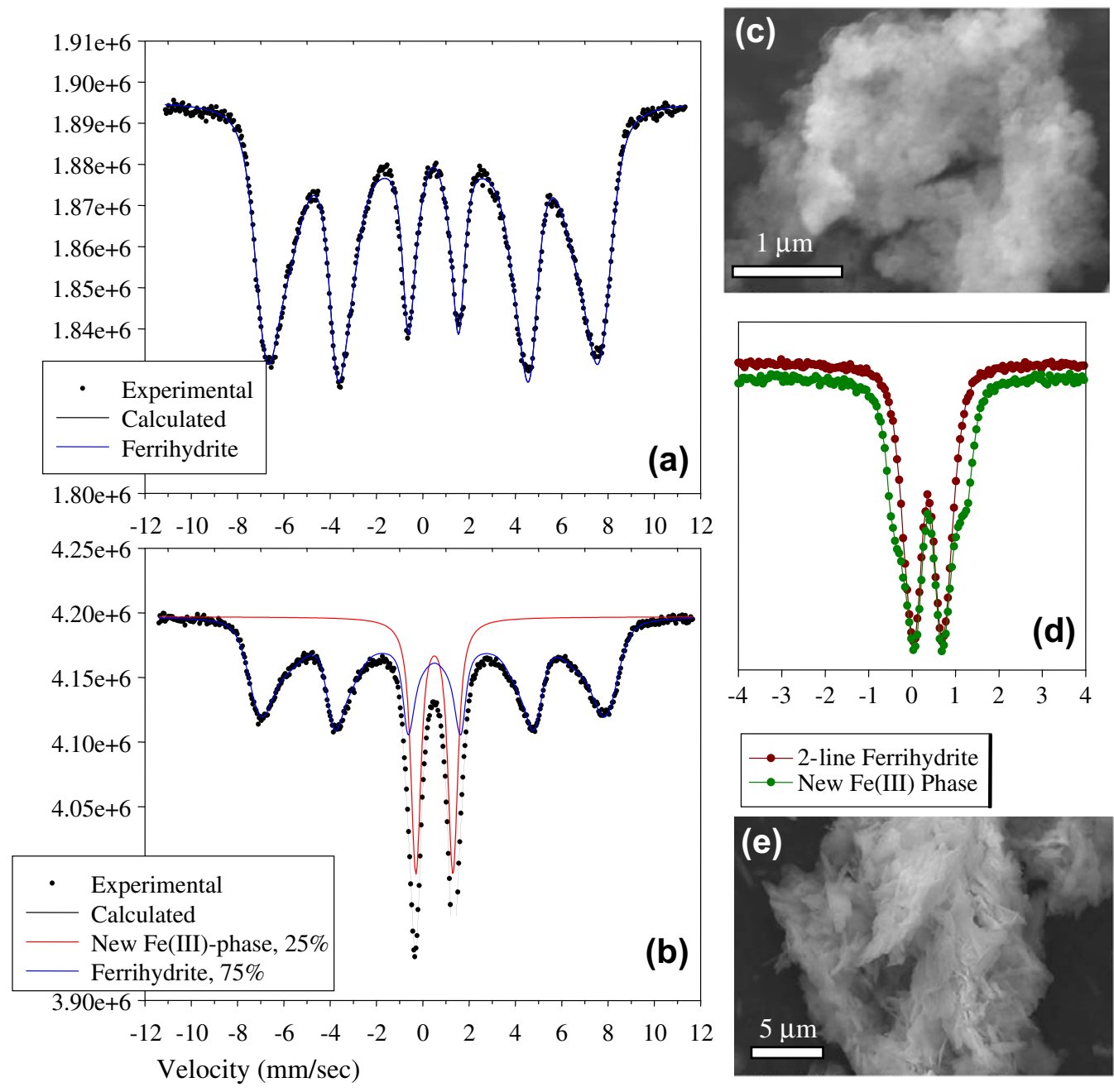

Fig. 1. $12 \mathrm{~K}$ Mössbauer spectra of starting ferrihydrite (a) and transformed mineral/s at $95{ }^{\circ} \mathrm{C}$ (b). Room temperature Mössbauer spectra of these two phases are shown in (d). SEM images of ferrihydrite (c) and transformed mineral/s (e) show growth of acicular crystals on very fine grained ferrihydrite.

Table 1

Summary of experimental set-up for $\mathrm{FeO}-\mathrm{PO}_{4}$ interaction experiment.

\begin{tabular}{llllc}
\hline $\begin{array}{l}\text { Experimental } \\
\text { temperature } \\
\left({ }^{\circ} \mathrm{C}\right)\end{array}$ & $\begin{array}{l}\text { Total } \\
\mathrm{PO}_{4} \\
(\mathrm{mmol} / \mathrm{L})\end{array}$ & $\begin{array}{l}\text { Starting } \\
\delta^{18} \mathrm{O} \text { of } \\
\mathrm{PO}_{4}(\%)\end{array}$ & $\begin{array}{l}\text { Ferrihydrite } \\
\text { concentration } \\
(\mathrm{g} / \mathrm{L})\end{array}$ & $\begin{array}{l}\text { Total } \\
\text { volume } \\
(\mathrm{L})\end{array}$ \\
\hline 4 & 78.0 & 12.7 & 10.0 & 0.8 \\
21 & 78.0 & 12.7 & 10.0 & 1.6 \\
21 & 3.1 & 33.9 & 0.5 & 0.5 \\
21 & 1.0 & 13.8 & 0.1 & 16.0 \\
70 & 78.0 & 12.7 & 10.0 & 1.6 \\
70 & 3.1 & 33.9 & 0.5 & 0.5 \\
95 & 78.0 & 12.7 & 10.0 & 1.6 \\
\hline
\end{tabular}

an artificial sea water medium (Gao and Mucci, 2003) and were stirred continuously using a magnetic stirrer. The $\mathrm{pH}$ of all experiments was periodically measured and maintained at $8.2( \pm 0.2)$ using $1 \mathrm{mM} \mathrm{NaOH}$. In each experiment, $50 \mu \mathrm{mol} / \mathrm{L}$ sodium azide was added to suppress microbial activities.
To better simulate natural oceanic environments, where the aqueous phosphate concentration is $\sim 3-4 \mu \mathrm{mol} / \mathrm{L}$ (Wheat et al., 1996; Colman et al., 2005), a third series of experiments was performed in HDPE carboys using $0.1 \mathrm{~g} / \mathrm{L}$ of ferrihydrite and a $20 \mathrm{~L}$ reaction volume. The carboy containers were periodically shaken to homogenize the sample. Other experimental parameters were held constant as described above. The measured equilibrium phosphate distribution showed that aqueous-phase phosphate remained at $3-13 \mu \mathrm{mol} / \mathrm{L}$ over the course of carboy experiments.

At selected time points, iron oxide-phosphate suspension was extracted from reaction vessels, and $1.5 \% \mathrm{Si}$ was added to limit iron-oxide mineral transformation, and aqueous and sorbed-phase phosphates were separated by centrifugation. The sorbed-phase phosphate with iron oxide was freeze dried, fully homogenized and stored for further analysis. A portion of the freeze dried mass was then extracted by dissolving iron oxide solids in 1 or $4 \mathrm{M} \mathrm{HCl}$ (depending on the ageing and crystallinity of minerals) for $24 \mathrm{~h}$. Concentrations of aqueous and sorbed phosphate phases were measured colorimetrically using a UV/vis 
spectrophotometer by the phosphomolybdate blue method (Murphy and Riley, 1962).

\subsection{Methods of aqueous and sorbed phosphate $O$-isotope analysis}

Aqueous and sorbed-phase phosphates were converted to silver phosphate for O-isotope analysis. The MAGIC (magnesium-induced phosphate co-precipitation) method (Karl and Tien, 1992 as modified by Colman et al., 2005) was used to reduce sample volume and concentrate phosphate in large-volume carboy experiments. Both aqueous and sorbed-phase phosphate from all series of experiments was purified using sequential precipitation and re-crystallization methods adapted from Luz and Kolodny (1985) and modified by Blake et al. (1998) and Liang and Blake (2007). In brief, dissolved phosphate was first precipitated as ammonium phosphomolybdate (APM), then re-crystallized as magnesium ammonium phosphate (MAP). MAP was dissolved and the resulting solution treated by cation resin exchange to remove $\mathrm{Mg}^{2+}$ and other cations. The purified phosphate solution produced by this method was finally converted to silver phosphate for $\mathrm{O}$-isotopic analysis. A separate phosphate standard was processed identically and in parallel with samples to confirm the validity of sample processing and reliability of isotopic results.

Phosphate O-isotope analyses were carried out at the Earth System Center for Stable Isotope Studies (ESCSIS) of the Yale Institute for Biospheric Studies. Silver phosphate was analyzed by online high-temperature thermal decomposition (Vennemann et al., 2002; Colman et al., 2005) using a Thermo-Chemolysis Elemental Analyzer $\left(\mathrm{TC} / \mathrm{EA}, 1450^{\circ} \mathrm{C}\right)$ coupled to a Delta $+\mathrm{XL}$ continuous flow isotope ratio monitoring mass spectrometer (Thermo-Finnigan, Bremen, Germany) with precision of $\pm 0.2-0.3 \%$. Phosphate $\mathrm{O}$-isotope ratios $\left(\delta^{18} \mathrm{O}_{\mathrm{P}}\right)$ were calibrated against conventional fluorination using different silver phosphate standards according to published methods (Vennemann et al., 2002). All O-isotope data are reported relative to the VSMOW standard in units of permil $(\%)$.

\subsection{XRD}

Both the synthesized ferrihydrite and minerals formed/ transformed during experiments were analyzed using XRD. Powder XRD patterns were obtained with a Philips PW3040/00 X'pert MPD system, using $\mathrm{Cu} K_{\alpha}$ radiation with a variable divergent slit and a solid-state detector. The routine power was $700 \mathrm{~W}(35 \mathrm{kV}, 20 \mathrm{~mA})$. The powdered samples were packed into the wells $(6.35 \mathrm{~mm}$ diameter and $0.8 \mathrm{~mm}$ deep) of low-background quartz XRD slides. The JADE+, V5 (Materials Data Inc., Livermore, California) software package was used for data analysis.

\section{5. ${ }^{57} \mathrm{Fe}-\mathrm{Mössbauer}$ spectroscopy}

Approximately $50 \mathrm{mg}$ of the sample was placed into a $\mathrm{Cu}$ sample holder that was sealed at one end with clear scotch tape and half-filled with petroleum jelly. The holder was then filled with petroleum jelly and sealed with scotch tape. An aluminized Mylar stable to liquid He temperature was used to seal each end of the holder. Both the tape and polymer were snapped into the holder with rings made of PEEK polymer for a tight fit. Mössbauer spectra were collected using a $50 \mathrm{mCi}$ (initial strength) ${ }^{57} \mathrm{Co} / \mathrm{Rh}$ source. The velocity transducer MVT-1000 (WissEL) was operated in a constant acceleration mode $(23 \mathrm{~Hz}, \pm 12 \mathrm{~mm} / \mathrm{s})$. An $\mathrm{Ar}-\mathrm{Kr}$ proportional counter analyzed transmitted radiation, and the counts were stored in a multichannel scalar (MCS) as a function of energy (transducer velocity) using a 1024 channel analyzer. Data were folded to 512 channels to give a flat background and a zero-velocity position corresponding to the center shift (CS) of a metal iron foil at room temperature (RT). Calibration spectra were obtained with a $25 \mathrm{~mm}$ thick $\alpha-\mathrm{Fe}(\mathrm{m})$ foil (Amersham, England) placed in the same position as the samples to minimize sample geometry errors. A closed-cycle cryostat (ARS, Allentown, PA) was employed for below-RT measurements. The Mössbauer data were modeled with the Recoil software (University of Ottawa, Canada) using a Voight-based structural fitting routine (Rancourt and Ping, 1991). The coefficient of variation of the spectral areas of the individual sites generally ranged between $1 \%$ and $2 \%$ of the fitted values.

\section{RESULTS}

\subsection{Properties of ferrihydrite and its transformation products}

XRD patterns and Mössbauer spectroscopy revealed that the starting mineral was pure 2-line ferrihydrite and SEM images showed uniform sized ferrihydrite nanoparticles (Fig. 1). For all experiments performed at $\leqslant 70{ }^{\circ} \mathrm{C}$ with identical starting materials, there were no detectable changes in the mineralogy and morphology of ferrihydrite over 1 year of reaction. In the $95^{\circ} \mathrm{C}$ experiment, ferrihydrite began to transform and by $\sim 2000 \mathrm{~h}$ of reaction, acicular crystals started to grow (Fig. $1 \mathrm{~b}$ and d). With this progressive change, ferrihydrite in the presence of phosphate changed into a new suite of minerals closely related to iron phosphate hydrate, potassium-magnesium phosphate and winchite.

${ }^{57} \mathrm{Fe}-\mathrm{Mössbauer}$ spectroscopy is a sensitive ${ }^{57} \mathrm{Fe}$ specific (natural abundance of $2.12 \%$ ) technique that provides information on oxidation state, coordination environment and magnetic properties of Fe-containing materials, irrespective of their crystallinity. Fig. 1 shows Mössbauer spectra of 2-line ferrihydrite (the starting material) and its transformation product at $95^{\circ} \mathrm{C}$ obtained at room temperature (RT) and 12-K, after 3-months. Spectra were obtained at different temperatures to quantify contributions of various species since temperature has a significant effect on magnetic properties of Fe-oxides, particularly 2-line ferrihydrite (Murad and Cashion, 2004). The modeled parameters of the starting material at RT (doublet pattern due to paramagnetic behavior - brown trace ${ }^{1}$, Fig. 1e) were identical to that of 2-line ferrihydrite (center shift $[\mathrm{CS}]=0.36$

\footnotetext{
${ }^{1}$ For interpretation of color mentioned in this figure the reader is referred to the web version of the article.
} 
$\mathrm{mm} / \mathrm{s}$ and quadrupole shift $[\mathrm{QS}]=0.62 \mathrm{~mm} / \mathrm{s}$ ). The RT spectrum of the transformation product was not modeled (the 12-K spectrum was modeled instead for better quantification; Fig. 1c) because the presence of two doublets in its spectrum was evident from the asymmetry of the pattern and the shoulders in its spectrum (green trace). This observation was consistent with XRD that showed peaks due to both 2-line ferrihydrite and to an unidentified Fe-phase (Fig. 1d). The broad sextet feature of 2-line ferrihydrite at 12-K (Fig. 1a) is consistent with its behavior at or below $77-\mathrm{K}$ where the doublet feature transforms to a sextet due to magnetic ordering. The 2-line ferrihydrite transformation product, on the other hand, is not magnetically ordered at $12-\mathrm{K}$ (center shift $[\mathrm{CS}]=0.48 \mathrm{~mm} / \mathrm{s}$ and quadrupole shift $[\mathrm{QS}]=1.68 \mathrm{~mm} / \mathrm{s} ; 25 \%$ spectral area, Fig. 1c). Mössbauer parameters of the product at RT are not consistent with P-substituted ferrihydrite (Thibault et al., 2009), while its $12-\mathrm{K}$ parameters are also not consistent with lepidocrocite $(\gamma-\mathrm{FeOOH})$ because lepidocrocite magnetically orders below 77-K (Murad and Cashion, 2004), the products normally expected under such experimental conditions. Further work is needed to identify this product more precisely.

\subsection{Kinetics of phosphate sorption and isotopic fractionation}

\subsection{1. $21^{\circ} \mathrm{C}$}

The rate of phosphate uptake by ferrihydrite and associated $\mathrm{PO}_{4} \mathrm{O}$-isotope fractionations at room temperature are shown in Fig. 2. This result shows that the initial uptake of phosphate is rapid with about $25 \%$ of the equilibrium sorbed phosphate concentration reached within 1 min of reaction. The uptake of phosphate then increased steadily to reach equilibrium at about $20 \mathrm{~h}$, with slow sorption kinetics observed at longer times. Such slow sorption following initially rapid uptake of phosphate has been observed previously (e.g., Berner, 1973; Torrent and Barron, 2000) and interpreted as sorption to micro-pores or grooves and within aggregates (Willett et al., 1988; Strauss et al., 1997). Since the extent of slow kinetics depends on the crystallinity of minerals (Strauss et al., 1997), this effect is expected to be more pronounced in low crystalline ferrihydrite. The $\mathrm{pH}$ of the system increased significantly at early phases of sorption, likely as a result of dehydroxylation of -OH groups (Lijklema, 1980).

The O-isotope fractionation during phosphate sorption shows that $\mathrm{P}^{16} \mathrm{O}_{4}$ phosphate is initially sorbed preferentially to ferrihydrite. The maximum fractionation $(-2.3 \%$ ) was observed in the first minute of sorption. This fractionation then gradually decreased, as a result of the continual concomitant exchange between aqueous and sorbed phases of phosphates. For example, the fractionation decreased to about $-0.6 \%$ in $70 \mathrm{~h}$ and remained fairly constant for the duration of the experiment.

Another set of experiments was performed at room temperature using isotopically heavy dissolved phosphate $\left(\delta^{18} \mathrm{O}\right.$ of $\mathrm{PO}_{4}=33.9 \%$ ) (Table 1 ) in order to understand the effect of initial oxygen isotopic composition of phosphate on the fractionation between aqueous and adsorbed phosphate phases. Results of this experiment also showed a similar extent of initial fractionation $(-2.5 \%)$ as in the experiment with light phosphate $\left(\delta^{18} \mathrm{O}\right.$ of $\mathrm{PO}_{4}=12.7 \%$ ). This fractionation gradually decreased with time and became $-0.5 \%$ at the end of the experiment. These small differences in $\Delta$ values measured at the end of these two labeled-phosphate experiments are within limits of analytical error. These results suggest that, irrespective of the original isotopic composition of oxygen in phosphates, the extent and kinetics of the isotopic fractionation between sorbed and aqueousphase phosphate are the same at a given temperature.

\subsection{2. $70^{\circ} \mathrm{C}$}

Both the partitioning and isotopic fractionation between sorbed and aqueous phosphate in experiments performed at $70^{\circ} \mathrm{C}$ were very similar to that at $21^{\circ} \mathrm{C}$. The minor difference, however, was a slightly higher extent of initial fractionation $(-2.9 \%)$ and faster decrease of this fractionation to $\sim 0.5 \%$ (within $<50 \mathrm{~h}$; Fig. 3), than that of experiments performed at lower temperatures. The nature of fractionation was very similar for both isotopically-light
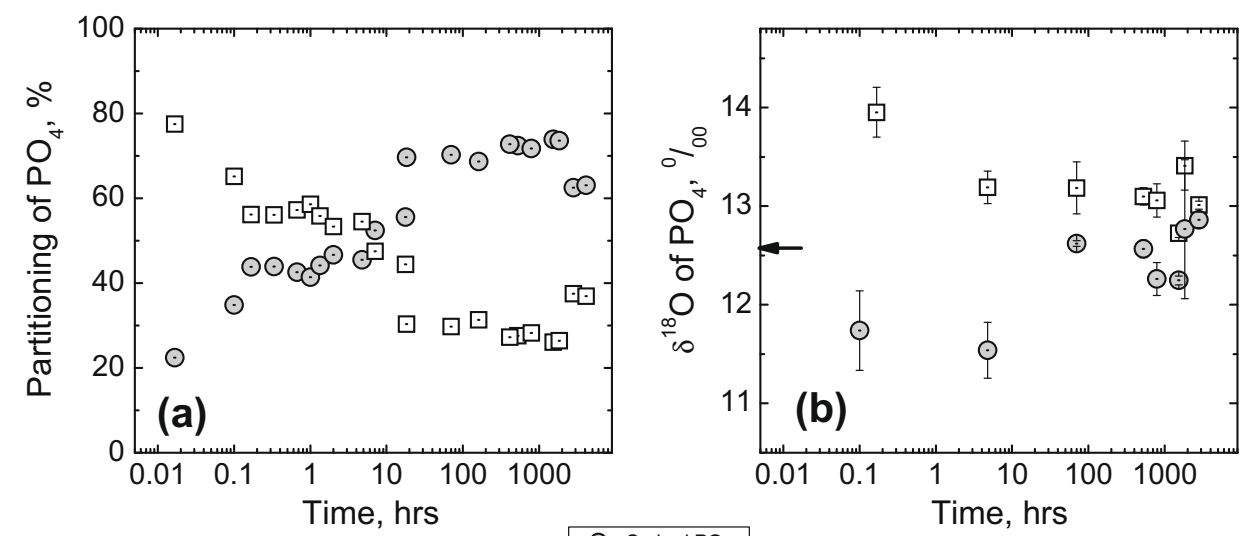

$\odot$ Sorbed $\mathrm{PO}_{4}$

Aqueous $\mathrm{PO}_{4}$

Fig. 2. (a) Partitioning of $\mathrm{PO}_{4}$ as a function of time during its sorption to ferrihydrite at $24{ }^{\circ} \mathrm{C}$. Experiments were performed in $78 \mathrm{mmol} / \mathrm{L}$ of $\mathrm{PO}_{4}$ at $10 \mathrm{~g} / \mathrm{L}$ ferrihydrite concentration in artificial sea water composition at $\mathrm{pH} 8.2( \pm 0.2)$, (b) fractionation of oxygen isotopes of sorbed and aqueous phosphate. The $\delta^{18} \mathrm{O}$ of starting $\mathrm{PO}_{4}(12.7 \%$ ) is shown by solid arrow. 

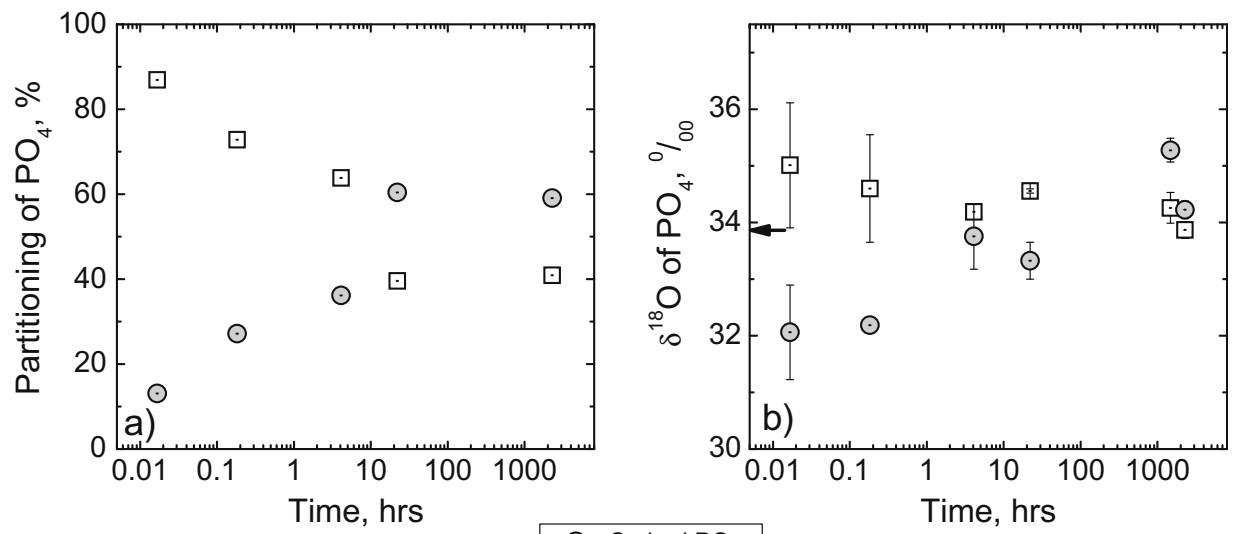

$\begin{array}{ll}\odot & \text { Sorbed } \mathrm{PO}_{4} \\ \square & \text { Aqueous } \mathrm{PO}_{4}\end{array}$

Fig. 3. (a) Partitioning of $\mathrm{PO}_{4}$ as a function of time during its sorption to ferrihydrite at $70{ }^{\circ} \mathrm{C}$. Experiments were performed in $3.1 \mathrm{mmol} / \mathrm{L}$ of $\mathrm{PO}_{4}$ at $1 \mathrm{~g} / \mathrm{L}$ ferrihydrite concentration in artificial sea water composition at $\mathrm{pH} 8.2( \pm 0.2)$, (b) fractionation of oxygen isotope of sorbed and aqueous phosphate. The $\delta^{18} \mathrm{O}$ of starting $\mathrm{PO}_{4}(33.9 \%$ oo is shown by solid arrow.

and heavy phosphates (i.e., initial $\delta^{18} \mathrm{O}$ of aqueous-phase $\mathrm{PO}_{4}$ of $12.7 \%$ and $33.9 \%$ )

\subsection{3. $95^{\circ} \mathrm{C}$}

Results of phosphate sorption experiments conducted at $95^{\circ} \mathrm{C}$ are shown in Fig. 4a. As in other low-temperature experiments, phosphate sorption is rapid, but the isotherm shows three sorption regimes at $95^{\circ} \mathrm{C}$ : (a) an initial rapid rate of sorption ( 0 to $\sim 20 \mathrm{~min}$ ) followed by, (b) a relatively slow rate of sorption ( $20 \mathrm{~min}-20 \mathrm{~h}$ ), and finally, (c) a gradual increase until equilibrium sorption is reached at $\sim 200 \mathrm{~h}$ of reaction. It is apparent that micro-pores and
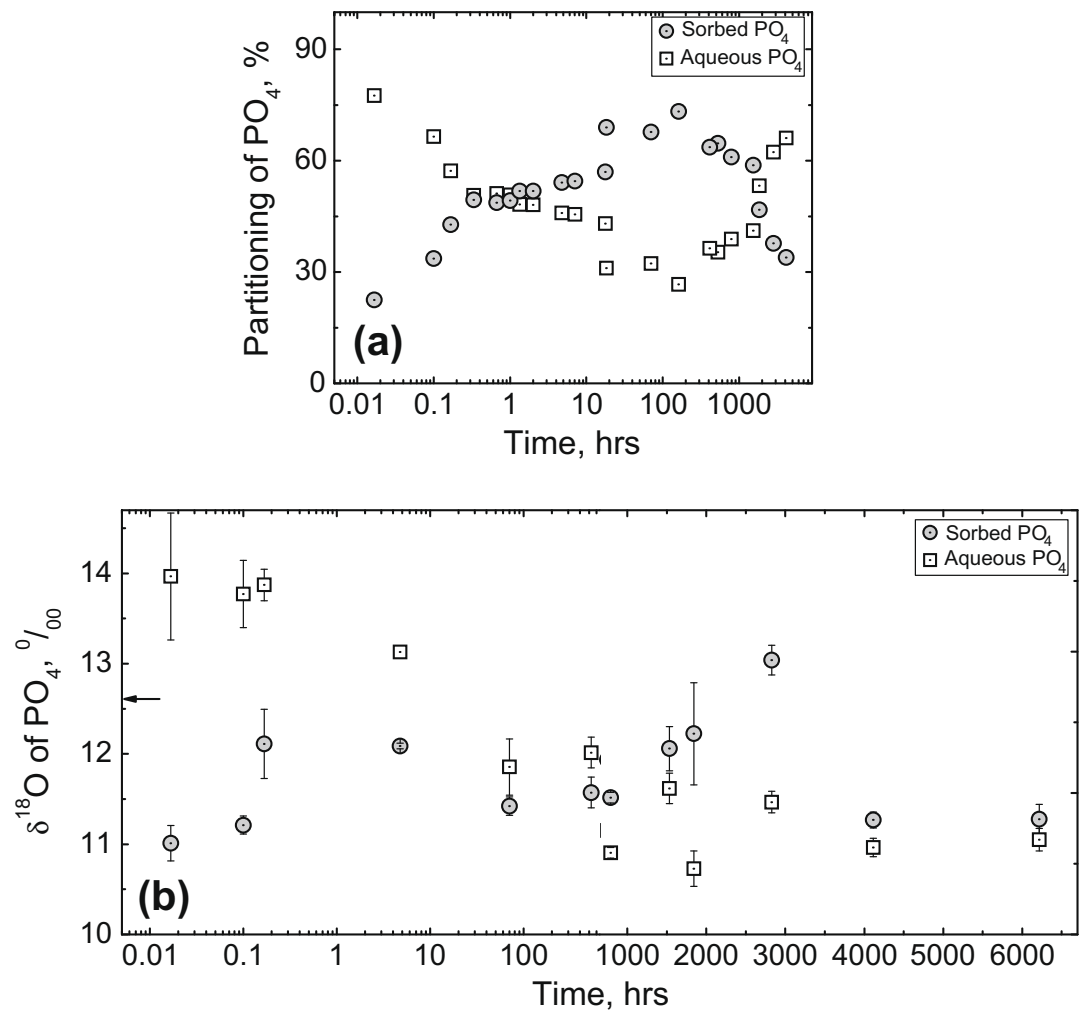

Fig. 4. (a) Partitioning of $\mathrm{PO}_{4}$ as a function of time during its sorption to ferrihydrite at $95{ }^{\circ} \mathrm{C}$. Experiments were performed in $78 \mathrm{mmol} / \mathrm{L}$ of $\mathrm{PO}_{4}$ at $10 \mathrm{~g} / \mathrm{L}$ ferrihydrite concentration in artificial sea water composition at $\mathrm{pH} 8.2( \pm 0.2)$, (b) fractionation of oxygen isotope of sorbed and aqueous-phase phosphate. The $x$-axis is drawn both in logarithmic and arithmetic scale to illustrate the fractionation during early sorption and mineral transformation. The $\delta^{18} \mathrm{O}$ of starting $\mathrm{PO}_{4}(12.7 \%)$ is shown by solid arrow. 
intra-aggregate voids in ferrihydrite contribute significantly to the observed slow sorption kinetics. Interestingly, after $200 \mathrm{~h}$ of reaction, the amount of sorbed phosphate decreased sharply suggesting the release of pre-sorbed phosphate. The amount of release was $\sim 60 \%$ at about $4200 \mathrm{~h}$ of incubation. Phosphate desorption occurs during the transition of ferrihydrite into more crystalline mineral phase/s as evidenced from XRD, Mössbauer spectroscopy and SEM image analyses. This is because mineral transformation of nanometer-sized ferrihydrite with high surface area to a more crystalline mineral phase/s requires the release of previously sorbed phosphate into solution. Therefore, this desorption after $\sim 1000 \mathrm{~h}$ reaction was related to the changes in sorption sites as a result of mineral conversion, including other possible effects such as different mechanisms of $\mathrm{PO}_{4}$ sorption to newly formed minerals (see Section 4).

As in lower temperature experiments, the fractionation of oxygen isotopes was observed only in the earliest phase of sorption. A key observation in the $95^{\circ} \mathrm{C}$ experiment was the occurrence of $\mathrm{O}$-isotope exchange between phosphate and water (promoted by temperature $>80^{\circ} \mathrm{C}$ ) during the phosphate desorption process. This result is consistent with previous observations of exchange of oxygen isotopes between water and dissolved phosphate at temperatures $\geqslant 80^{\circ} \mathrm{C}$ on laboratory timescales (Tudge, 1960; Lecuyer et al., 1999; O’Neil et al., 2003). Furthermore, mineral transformation was readily observed at this temperature which gave an opportunity to characterize phosphate-mineral interactions during this transformation. Our results show that the progressive transformation of ferrihydrite to other more stable minerals results in the preferential desorption of $\mathrm{PO}_{4}$ enriched in the lighter isotope, ${ }^{16} \mathrm{O}$. Further transformations to even more crystalline Fe-oxides such as hematite would be expected to result in similar results, which are described more fully in Section 4 . This preferential desorption and fractionation begins at the onset of mineral transformation and persists, perhaps until complete mineral transformation. However, it is important to note that the difference in the isotopic composition between aqueous and sorbed phosphate phases becomes gradually smaller and finally negligible within error.

To detect the occurrence of phosphate-water oxygen isotope exchange, the $\delta^{18} \mathrm{O}$ values of water in experimental systems was also measured periodically at all experimental temperatures. The oxygen isotope compositions of ${ }^{18} \mathrm{O}$ labeled waters remained nearly constant over the course of all experiments performed at $\leqslant 70^{\circ} \mathrm{C}$, indicating insignificant oxygen isotope exchange between $\left(\mathrm{PO}_{4}\right)_{\mathrm{aq}}$ and $\mathrm{H}_{2} \mathrm{O}$. Extrapolation of phosphate-water exchange rates measured by O'Neil et al. (2003) to $95^{\circ} \mathrm{C}$ gives the equilibrium fractionation between phosphate and water at $95^{\circ} \mathrm{C}$ and $\mathrm{pH} 8.1( \pm 0.2)$ as about $9 \%$. This means that the original $\Delta\left(\delta^{18} \mathrm{O}_{\mathrm{PO} 4}-\delta^{18} \mathrm{O}_{\mathrm{H} 2 \mathrm{O}}=18.2 \%\right)$ was $\sim 9.2 \%$ away from equilibrium. Therefore the observed decrease in the $\delta^{18} \mathrm{O}$ value of phosphate by $1.1 \%$ (Fig. 4) at the end of the experiment is justifiable.

It must be emphasized that the bulk phosphate isotopic composition cannot resolve specific interactions such as separate interactions of phosphate with ferrihydrite and newly forming minerals during desorption, or sorption processes occurring during progressive mineral transformation. It is clear from these data, however, that the cumulative isotope effect of this transformation is the initial preferential desorption of $\mathrm{P}^{16} \mathrm{O}_{4}$. Overall, the extent of fractionation and re-equilibration during the transformation is similar to that during sorption of phosphate to clean ferrihydrite surfaces. Therefore the final phases of both sorbed and aqueous-phase phosphate has similar isotopic composition.

\subsection{4. $4{ }^{\circ} \mathrm{C}$}

Partitioning of phosphate between aqueous and solid phases during sorption to ferrihydrite at $4{ }^{\circ} \mathrm{C}$ as a function of time is shown in Fig. 5a. This result shows that the initial uptake of phosphate is slow relative to higher temperature experiments. Similarly, the slow sorption kinetics observed in high-temperature experiments is not as pronounced at $4{ }^{\circ} \mathrm{C}$. The extent and rate of $\mathrm{O}$-isotopic fractionation between sorbed and aqueous-phase phosphate during

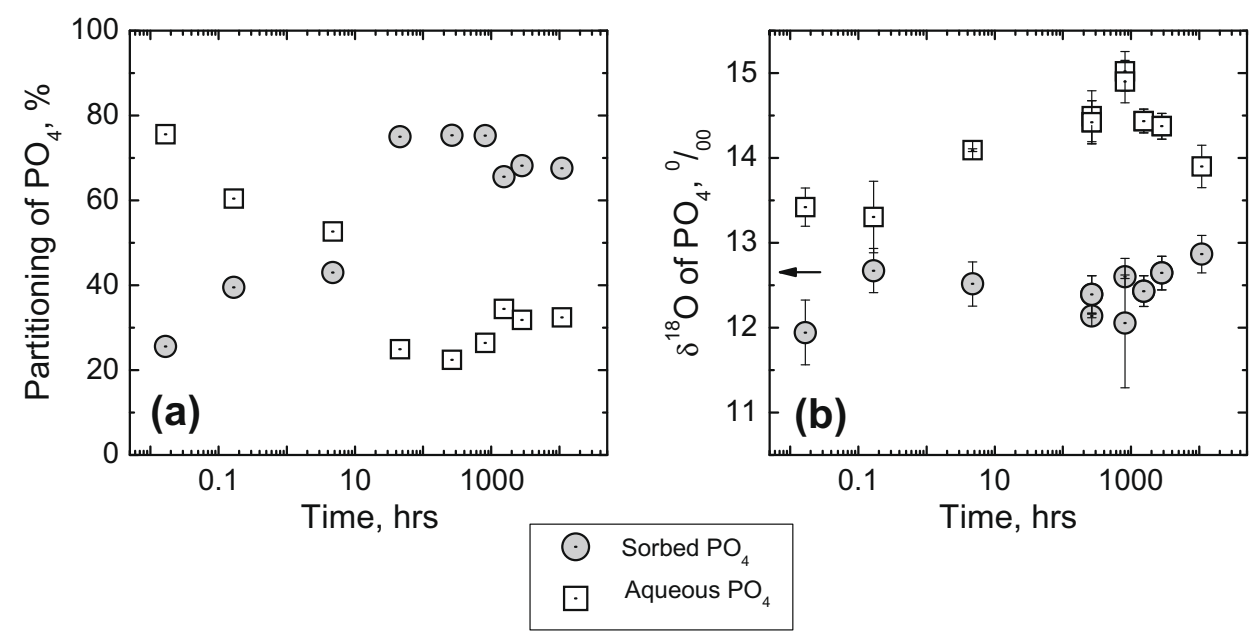

Fig. 5. (a) Partitioning of $\mathrm{PO}_{4}$ as a function of time during its sorption to ferrihydrite at $4{ }^{\circ} \mathrm{C}$. Experiments were performed in $78 \mathrm{mmol} / \mathrm{L}$ of $\mathrm{PO}_{4}$ at $10 \mathrm{~g} / \mathrm{L}$ ferrihydrite concentration in artificial sea water composition at $\mathrm{pH} 8.2( \pm 0.2)$, (b) fractionation of oxygen isotope of sorbed and aqueous phosphate. The $\delta^{18} \mathrm{O}$ of starting $\mathrm{PO}_{4}(12.7 \%$ o $)$ is shown by solid arrow. 
uptake by ferrihydrite (Fig. 5b) show that fractionation occurred only at the early phase of sorption with lighter phosphate, $\mathrm{P}^{16} \mathrm{O}_{4}$, enriched preferentially in the sorbed phase, as was observed at all other temperatures studied. Consistent with high-temperature experiments, this fractionation gradually decreased over time, but at a slower rate. The $\Delta$ value at the end of the experiment (i.e., $10,800 \mathrm{~h}$ or 15 months) was $-1.4 \%$. However, the isotopic composition of sorbed phosphate, calculated from isotope mass balance, would be higher than the measured value. In this case, the $\Delta$ value will be lower than $-1.4 \%$. A key attribute at this temperature (compared to higher temperatures) is that the rate of phosphate exchange between the sorbed and aqueous-phase phosphate is much slower than that at higher temperatures, and did not reach equilibrium within 15 months of incubation.

\subsubsection{Fractionation of phosphate at low phosphate concentrations}

Experiments performed in $20 \mathrm{~L}$ HDPE carboys at low iron oxide and phosphate concentrations (with 3-11 $\mu \mathrm{mol} / \mathrm{L}$ aqueous phosphate) simulating ocean water environments also show that isotopic fractionation between sorbed and aqueous phosphate occurs only during the very early phase of rapid sorption (Fig. 6). The measured $\Delta$ $\left(\delta^{18} \mathrm{O}_{\mathrm{srb}}-\delta^{18} \mathrm{O}_{\mathrm{aq}}\right)$ value was about $-2 \%$ within $2 \mathrm{~h}$ of mixing and this value decreased continuously with the progress of reaction and became $\sim-1.0 \%$ in $2660 \mathrm{~h}$. The overall trend of isotopic fractionation is similar to room temperature experiments performed at high phosphate concentration, but took longer to re-equilibrate after the early phase of kinetic isotopic fractionation.

\section{DISCUSSION}

\subsection{Kinetics of mineral transformation and its effect on partitioning of phosphate}

Ferrihydrite is a metastable mineral and converts to other more stable minerals. The rate of this transformation depends on solution chemistry, temperature, $\mathrm{pH}$ and the

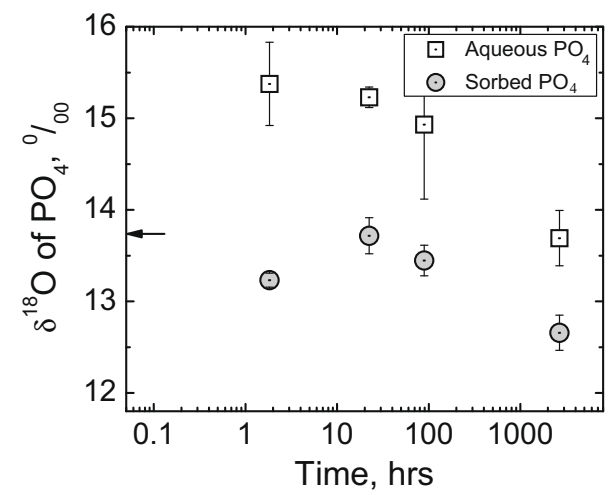

Fig. 6. Fractionation oxygen isotopes in $\mathrm{PO}_{4}$ during experiments performed at low $\left(10 \mu \mathrm{m} / \mathrm{L}\right.$ aqueous $\mathrm{PO}_{4}$ concentration. Experiments were performed in $1 \mathrm{mmol} / \mathrm{L}$ of $\mathrm{PO}_{4}$ at $0.1 \mathrm{~g} / \mathrm{L}$ ferrihydrite concentration with total reaction volume of $20 \mathrm{~L}$ in artificial sea water composition at $\mathrm{pH} 8.2( \pm 0.2)$. nature of sorbed complexes among other factors (Cornell and Schwertmann, 2003). However, the sorption of phosphate, like other oxyanions, increases the entropic component of free energy of activation (Shaw et al., 2005) and, therefore hinders ferrihydrite dissolution (Biber et al., 1994) and mineral transformation. Since the P/Fe molar ratio in our first series of experiments $(\sim 0.7)$ was much higher than the minimum required for effective inhibition $(>0.015$, Galvez et al., 1999), extensive inhibition of mineral transformation was expected. In fact, the rate of mineral transformation in our study decreased by more than two orders of magnitude compared with phosphate-free systems (Shaw et al., 2005). Although phosphate is released concomitant with ferrihydrite dissolution (Fig. 4), it sorbs again to the newly-precipitating minerals. This sorption to new mineral may again inhibit crystal growth because of the sorption of phosphate onto reactive surface sites. Our results clearly show the presence of these simultaneously occurring reactions (Fig. 4).

Mineral transformation at $95^{\circ} \mathrm{C}$ also affected the partitioning of phosphate. For example, aqueous-phase phosphate steadily increased as a result of this transformation (Fig. 4). This increase is consistent with the changes in surface area as a result of mineral transformation. As shown in SEM images (Inset in Fig. 1), the large surface area of ferrihydrite (ca. $790 \mathrm{~m}^{2} / \mathrm{g}$; Borch et al., 2007) decreases by more than an order of magnitude when it converts to more stable mineral phases (such as Jaisi et al., 2009). This decrease in surface area requires the release of pre-sorbed phosphate. Therefore, the sorbed phosphate is released during ferrihydrite dissolution and re-sorbed to newly precipitated minerals, apart from its partial consumption to form new phosphate minerals.

\subsection{Isotopic effects of phosphate sorption}

Experiments performed at different concentrations of ferrihydrite and phosphate with different isotopically-labeled oxygen showed a strong kinetic fractionation between sorbed and aqueous-phase phosphates during the early phase of sorption. Nearly constant steady state isotopic fractionation $(\Delta=\sim-2.2 \%$ to $-2.5 \%$ o $)$ in the early stage of phosphate sorption in all experiments, irrespective of temperature and initial isotopic composition of phosphate, suggests negligible temperature-dependence on isotopic fractionation. However, this fractionation continuously decreased with time due to isotopic exchange between aqueous and sorbed-phase phosphates and became almost negligible with sufficient equilibration/exchange time. This type of kinetic fractionation during the early sorption phase has been found in several metal isotopes such as $\mathrm{Fe}, \mathrm{Zn}, \mathrm{Mo}$ and Tl (Rehkämper et al., 2002; Siebert et al., 2003; Johnson et al., 2005; Juillot et al., 2008). For many cation species such as $\mathrm{Fe}^{2+}, \mathrm{Zn}^{2+}$ and $\mathrm{Tl}^{3+}$, heavy isotopes are preferentially sorbed to mineral or sediment surfaces. But for anionic species such as $\mathrm{MoO}_{2}{ }^{4-}$ and $\mathrm{PO}_{4}{ }^{3-}$, light isotopes are preferentially sorbed to mineral/sediment surfaces (Siebert et al., 2003). Other oxyanions such as selenite and sulfate also show similar results as that of phosphate but the fractionation is very small (within $0.5 \%$, van Stempvoort 
et al., 1990; Johnson et al., 2000). This difference in selective fractionation between anion and cationic species is probably related to the element in question $(\mathrm{O}$ atom or metal ions) making bonds to the mineral/sediment surfaces.

Partitioning of phosphate is $\mathrm{pH}$ dependant and the degree of its protonation increases with decreasing $\mathrm{pH}$. It has been found that the equilibrium ${ }^{18} \mathrm{O} /{ }^{16} \mathrm{O}$ ratios in aqueous phosphate increase with increasing degree of protonation of phosphate partly due to the relative magnitudes of the dissociation constants of the protonated species (O’Neil et al., 2003). Since the experimental $\mathrm{pH}$ was continuously monitored and maintained at $\mathrm{pH} 8.2( \pm 0.2)$ in our experiments, phosphate species should be dominantly $\mathrm{HPO}_{4}{ }^{2-}$ (O'Neil et al., 2003). Therefore, the observed fractionation is not a result of phosphate speciation. These findings are consistent with the preferential removal of $\mathrm{P}^{16} \mathrm{O}_{4}$ from the aqueous phosphate phase during initial precipitation of apatite (Liang and Blake, 2007).

Our study shows that the fractionation of oxygen isotopes is strictly a function of time during sorption of phosphate and during mineral transformation. However, the maximum initial kinetic isotopic fractionation measured in this study is higher than that during apatite precipitation (Liang and Blake, 2007). Although the relationship between fractionation associated with sorption and co-precipitation is not yet known, a likely explanation for the higher fractionation observed during sorption in our experiments is that our experiments had higher temporal resolution of reaction kinetics and because the highest fractionation occurs during the first moments of the experiment when sorption begins.

The final $\Delta(-1.3 \%$ o between solid and aqueous-phase phosphate in low-temperature experiments (at $4{ }^{\circ} \mathrm{C}$ ), typical of ocean bottom settings, was larger than that in high-temperature experiments (i.e., $\Delta=\sim-0.5 \%$ ). From the observed trend in our study, it is expected that this difference will gradually decrease over time and will probably become close to that measured in higher temperature experiments. This, in fact, is consistent with measurements of $\delta^{18} \mathrm{O}_{\mathrm{P}}$ from modern seafloor hydrothermal iron oxides, and ambient sea water DIP (Colman et al., 2005). For example, $\delta^{18} \mathrm{O}_{\mathrm{P}}$ value of phosphate sorbed to abiotic iron oxides formed from oxidation of black smoker plume particles at $9{ }^{\circ} \mathrm{N}$ East Pacific Rise (EPR) is $24.3( \pm 0.4) \%$ and dissolved phosphate in ambient Pacific sea water is 24.1 $( \pm 0.5) \%$. This key result suggests that prolonged exposure of iron oxides to dissolved phosphate (i.e., DIP in ambient sea water) and sufficient exchange of aqueous and sorbed phosphate in low-temperature $\left(\sim 2-4{ }^{\circ} \mathrm{C}\right)$ ocean bottom environments, results in no isotopic fractionation between the two phosphate phases. Therefore, irrespective of phases, both sorbed (to iron oxides) or aqueous (DIP), phosphates record the temperature information of ambient sea water. If the isotopic signature of iron oxide bound phosphates is preserved over time, then phosphate retained in iron oxides can be used to interpret ancient ocean environments.

\subsection{Isotopic fractionation during mineral transformation}

Oxygen isotope compositions of sorbed and aqueous phosphate during mineral transformation in $95^{\circ} \mathrm{C}$ experi- ments revealed an apparent isotopic fractionation indicating that $\mathrm{P}^{16} \mathrm{O}_{4}$ is preferentially desorbed. Transformation of ferrihydrite is primarily a dissolution-precipitation reaction (Schwertmann and Murad, 1983; Cornell and Schwertmann, 2003). If ferrihydrite transformation in our experiments followed this pathway, then measured isotopic results should reflect the cumulative effects of isotopic fractionation during ferrihydrite dissolution and formation of new minerals. Because this conversion is not a single time event, the isotopic fractionation is expected to continue to change over time. Interestingly, the maximum isotopic fractionation $(-2.4 \%$ observed during this process is equal to that which occurred during the initial stages of phosphate sorption to ferrihydrite. The major difference, however, is that the isotopic fractionation persisted for longer times (more than $2000 \mathrm{~h}$ ) during mineral transformation compared to a very limited time $(<100 \mathrm{~h})$ required during initial sorption of phosphate to ferrihydrite. It is implied from this result that the dissolution likely initiated with ferrihydrite crystallites containing isotopically-light sorbed phosphate. In fact, light phosphate is required to be released from sorption sites so that heavy phosphate concentrates in residual ferrihydrite. Although congruent dissolution of goethite and hematite does not involve iron isotopic fractionation (Skulan et al., 2002; Brantley et al., 2004), it is likely that ferrihydrite dissolution, in our case, is incongruent as a result of surface coverage with isotopically variable phosphate, if not selective sorption to different reactive sites of ferrihydrite. Under this condition, as a result of desorption, aqueous-phase phosphate becomes lighter than sorbed phosphate, consistent with our experimental results (Fig. 4). It is intuitive to expect that light isotopes are preferentially sorbed to newly formed minerals, but the desorption process should have dominated the overall signal due to the limited number of sorption sites in new more stable minerals compared with ferrihydrite.

\subsection{Mechanism of phosphate sorption}

An important phenomenon observed in this study is the nature of specific phosphate interaction with ferrihydrite and transformed minerals during sorption and desorption processes. Inner sphere complexation of phosphate to ferrihydrite (Sigg and Stumm, 1981) requires displacement of structural oxygen in oxides. In complexation reactions, either an oxygen atom from ferrihydrite or from phosphate is required to be displaced and released to solution (as intact $\mathrm{PO}_{4}$ groups). Similarly, during dissolution of ferrihydrite, phosphate groups are also concurrently released to solution. Resorption of phosphate to new mineral/s repeats the above process. Similarly, the exchange of oxygen between iron oxide and water is rapid while fractionation of oxygen isotopes between water and different iron oxides is small (1000 $\ln \alpha$ varies from $-3.8 \%$ to $+2.5 \%$, Bao and Koch, 1999). Therefore, any changes in the oxygen isotope composition of ferrihydrite are reflected by corresponding changes in the $\delta^{18} \mathrm{O}$ value of water especially at high ferrihydrite:water ratio experiments. This means that if $\mathrm{O}$-isotope exchange (involving breaking and reformation of $\mathrm{P}-\mathrm{O}$ bonds) between oxygen atoms in phosphate and $\mathrm{O}$ atoms in 
iron oxides occurred during any of the sorption, desorption and mineral transformation processes, then the $\delta^{18} \mathrm{O}$ value of phosphate should move toward the water or Fe-oxide value. Our experimental results for all temperatures and conditions showed that the isotopic composition of water remained constant and unchanged from the starting $\delta^{18} \mathrm{O}$ value $(-5.5 \%)$.

On the other hand, corresponding oxygen isotope compositions of iron oxides and water would increase toward phosphate $\delta^{18} \mathrm{O}$ values. Although the isotopic composition of water is not expected to change to a measurable extent because of high water:phosphate ratios (with molar ratio of $\mathrm{O}$ in $\mathrm{PO}_{4}: \mathrm{H}_{2} \mathrm{O}=185.9$ ) used in our experiments, our results consistently show that the isotopic composition of phosphate did not shift (to became close to that of water). This result, therefore, suggests that $\mathrm{P}-\mathrm{O}$ bonds do not break during the sorption/desorption process, but rather the entire $\mathrm{PO}_{4}$ units (irrespective of ${ }^{18} \mathrm{O}$ or ${ }^{16} \mathrm{O}$ or the different combinations of ${ }^{18} \mathrm{O}$ and ${ }^{16} \mathrm{O}$ in $\mathrm{PO}_{4}$ ) are sorbed or kicked off intact. This suggests that the ligand exchange is compensated by oxygen atoms entirely from ferrihydrite or from water. This results is quite different from sorption of other oxyanions to iron oxides such as selenite (Saeki and Matsumoto, 1998) where ligand exchange during sorption of selenite to geothite was found to release $6-40 \%$ of oxygen atoms from surface hydroxyl groups in geothite into the solution. Selenite has been considered as a phosphate analogue with respect to chemical interactions and identical mechanisms of sorption to iron oxides has been invoked (Manceau and Charlet, 1994). Our results, therefore, further support previous observations that the oxygen bond to phosphate in $\mathrm{PO}_{4}$ is robust and does not undergo isotopic exchange during these low-temperature reactions and processes.

\section{CONCLUSIONS AND IMPLICATIONS}

Several experiments performed at different solid-solution ratios and concentrations and oxygen isotopic compositions of phosphate between 4 and $95^{\circ} \mathrm{C}$, consistently showed temperature-independent fractionation between sorbed and aqueous phosphate at initial stages of non-equilibrium sorption. However, there was sufficient isotopic exchange between aqueous and sorbed phases of phosphate such that end products had similar isotopic compositions with small $(1.4 \%)$ to negligible $(0.2 \%)$ apparent fractionation between aqueous and sorbed phosphate phases. This isotopic exchange is also present during mineral transformation. Therefore it is expected that progressive transformation of ferrihydrite into more stable minerals such as hematite could still result in similar isotopic compositions of both sorbed and aqueous-phase phosphate. Therefore, $\delta^{18} \mathrm{O}$ values of dissolved phosphate in sea water may be preserved during their sorption to iron-oxide minerals such as hydrothermal plume particles, making marine iron oxides an important potential new proxy for dissolved phosphate in the oceans. This is an important and significant finding for the interpretation of oxygen isotope ratios of phosphate from biotic as well as abiotic systems (e.g., hydrothermal plumes), and in paleoenvironmental/paleotemperature studies.

\section{ACKNOWLEDGEMENTS}

This research was supported by grants from the American Chemical Society Petroleum Research Fund (45641AC2) and NSF (EAR-0746241) to R.E.B., and EMSL Internal Grant from Pacific Northwest National Laboratory and Interdepartmental Bateman Postdoctoral Fellowship from Yale University to D.P.J. Mossbauer analysis and XRD measurements of the samples were performed using EMSL, a national scientific user facility sponsored by the Department of Energy's Office of Biological and Environmental Research located at Pacific Northwest National Laboratory. We thank Gerard Olack for his meticulous assistance with O-isotope analyses and several constructive discussions during the project.

\section{REFERENCES}

Bao H. M. and Koch P. L. (1999) Oxygen isotope fractionation in ferric oxide-water systems: low temperature synthesis. Geochim. Cosmochim. Acta 63, 599-613.

Berner R. A. (1973) Phosphate removal from sea water by adsorption on volanogenic ferric oxide. Earth Plan. Sci. Lett. 18, $77-86$.

Biber M. V., de Silva A. M. and Stumm W. (1994) The coordination chemistry of weathering: IV. Inhibition of the dissolution of oxide minerals. Geochim. Cosmochim. Acta 56, 1999-2010.

Blake R. E., O’Neil J. R. and Garcia G. A. (1997) Oxygen isotope systematics of microbially mediated reactions of phosphate: I. Degradation of organophosphorus compounds. Geochim. Cosmochim. Acta 61, 4411-4422.

Blake R. E., O'Neil J. R. and Garcia G. A. (1998) Effects of microbial activity on the $\delta 18 \mathrm{OP}$ of dissolved inorganic phosphate and textural features of synthetic apatite. Am.Miner. 83, $1516-1531$.

Blake R. E., Alt J. C. and Martini A. M. (2001) Oxygen isotope ratios of PO4: an inorganic indicator of enzymatic activity and $\mathrm{P}$ metabolism and a new biomarker in the search for life. PNAS 98, 2148-2153.

Blake R. E., O'Neil J. R. and Surkov A. (2005) Biogeochemical cycling of phosphorus: insights from oxygen isotope effects of phosphoenzymes. Am. J. Sci. 305, 596-620.

Borch T., Sue Y., Kukkadapu R. and Fendorf S. (2007) Phosphate imposed limitations on biological reduction and alteration of ferrihydrite. Environ. Sci. Technol. 41, 166-172.

Brantley S. L., Liermann L. J., Guynn R. L., Anbar A., Icopini G. A. and Barling J. (2004) Fe isotopic fractionation during mineral dissolution with and without bacteria. Geochim. Cosmochim. Acta 68, 3189-3204.

Colman A. S., Blake R. E., Karl D. M., Fogel M. L. and Turekian K. K. (2005) Marine phosphate oxygen isotopes and organic matter remineralization in the oceans. PNAS 102, 13023-13028.

Cornell R. M. and Schwertmann U. (2003) The Iron Oxides: Structure, Properties, Reactions, Occurrence and Uses. VHC, New York.

Emerson D. and Moyer C. L. (2002) Neutrophilic Fe-oxidizing bacteria are abundant at the Loihi seamount hydrothermal vents and play a major role in $\mathrm{Fe}$ oxide deposition. Appl. Environ. Microb. 68, 3085-3093.

Galvez N., Barron V. and Torrent J. (1999) Effect of phosphate on the cystallization of hematite, geothite and lepidocrosite from ferrihydrite. Clays Clay Miner. 47, 304-311.

Gao Y. and Mucci A. (2003) Individual and competitive adsorption of phosphate and arsenate on goethite in artificial seawater. Chem. Geol. 199, 91-109. 
Jaisi D. P., Dong H., Plymale A. E., Frederickson J. K., Zachara J. M., Heald S. E. and Liu C. (2009) Reduction and long-term immobilizationof technetium by $\mathrm{Fe}(\mathrm{II})$ associated with clay mineral nontronite. Chem. Geol. 264, 127-138.

Johnson T. M., Bullen T. D. and Zawislanski P. T. (2000) Selenium stable isotope ratios as indicators of sources and cycling of selenium: results from the northern reach of San Francisco Bay. Environ. Sci. Technol. 34, 2075-2079.

Johnson C. M., Roden E. E., Welch S. A. and Beard B. L. (2005) Experimental constraints on $\mathrm{Fe}$ isotope fractionation during magnetite and $\mathrm{Fe}$ carbonate formation coupled to dissimilatory hydrous ferric oxide reduction. Geochim. Cosmochim. Acta 69 , 963-993.

Juillot F., Marechal C., Ponthieu M., Cacaly S., Morin G., Benedetti M., Hazemann J. L., Proux O. and Guyot F. (2008) $\mathrm{Zn}$ isotopic fractionation caused by sorption on goethite and 2lines ferrihydrite. Geochim. Cosmochim. Acta 72, 4886-4900.

Lecuyer C., Greansjean P. and Sheppard M. F. (1999) Oxygen isotope exchange between dissolved phosphate and water at temperatures $\leqslant 135^{\circ} \mathrm{C}$ : inorganic versus biological fractionations. Geochim. Cosmochim. Acta 63, 855-862.

Liang Y. and Blake R. E. (2007) Oxygen isotope fractionation between apatite and dissolved aqueous phosphate: $20-45^{\circ} \mathrm{C}$. Chem. Geol. 238, 121-133.

Lijklema L. (1980) Interaction of orthophosphate with iron(III) and aluminium hydroxides. Environ. Sci. Technol. 14, 537-541.

Luz B. and Kolodny Y. (1985) Oxygen isotope variations in phosphate of biogenic apatites: IV. Mammal teeth and bones. Earth Plan. Sci. Lett. 75, 29-36.

Manceau A. and Charlet L. (1994) The Mechanism of selenate adsorption on goethite and hydrous ferric oxide. J. Colloid Interf. Sci. 168, 87-93.

Markel D., Kolodny Y., Luz B. and Nishri A. (1994) Phosphorus cycling and phosphorus sources in Lake Kinneret: tracing by oxygen isotopes in phosphate. Israeli J. Earth Sci. 43, 165-178.

McLaughlin K., Cade-Menun B. J. and Paytan A. (2006) The oxygen isotopic composition of phosphate in Elkhorn Slough, California: a tracer for phosphate sources. Estuar. Coast. Shelf Sci. 70, 499-506.

Murad E. and Cashion J. (2004) Mössbauer Spectroscopy of Environmental Materials and their Industrial Utilization. Kluwer Academic Publishers.

Murphy J. and Riley J. P. (1962) A modified single solution method for the determination of phosphate in natural water. Anal. Chem. Acta 27, 31-36.

O'Neil J. R., Vennemann T. W. and Mckenzie W. F. (2003) Effects of speciation on equilibrium fractionations and rates of oxygen isotope exchange between $\left(\mathrm{PO}_{4}\right)_{\mathrm{aq}}$ and $\mathrm{H}_{2} \mathrm{O}$. Geochim. Cosmochim. Acta 67, 3135-3144.

Paige C. R., Snodgrass W. J., Nicholson R. V., Scharer J. M. and He Q. H. (1997) Effect of phosphate on the transformation of ferrihydrite into crystalline products in alkaline media. Water Air Soil Pol. 97, 394-412.

Paytan A., Luz B., Kolodny Y. and Neori A. (2002) Biologically mediated oxygen isotope exchange between water and phosphorus. Glob. Biogeochem. Cycle 16, 13-17.

Rancourt D. G. and Ping J. Y. (1991) Voigt-based methods for arbitrary-shape static hyperfine parameter distributions in Mössbauer-spectroscopy. Nucl. Instr. Meth. B 58, 85-97.
Rehkämper M., Frank M., Hein J. R., Porcelli D., Halliday A., Ingri J. and Liebetrau V. (2002) Thallium isotope variations in seawater and hydrogenetic, diagenetic and hydrothermal ferromanganese deposits. Earth Planet Sci. Lett. 197, 65-81.

Saeki K. and Matsumoto S. (1998) Mechanisms of ligand exchange reactions involving selenite sorption on goethite labeled with oxygen-stable isotope. Comm. Soil Sci. Plant Anal. 29, 30613072 .

Shaw S., Pepper S. E., Bryan N. D. and Livens F. R. (2005) The kinetics and mechanisms of the transformation of 2-line ferrihydrite to goethite and hematite under alkaline conditions, and in the presence of phosphate. Am. Mineral. 90, 1852-1860.

Siebert C., Nagler T. F., von Blanckenburg V. and Kramers J. D. (2003) Molybdenum isotope records as a potential new proxy for paleoceanography. Earth Planet. Sci. Lett. 211, 159-171.

Sigg L. and Stumm W. (1981) The interaction of anions and weak acids with the hydrous goethite $(\alpha-\mathrm{FeOOH})$ surface. Colloid Surf. A 2, 101-117.

Skulan J. L., Beard B. L. and Johnson C. M. (2002) Kinetic and equilibrium $\mathrm{Fe}$ isotope fractionation between aqueous $\mathrm{Fe}(\mathrm{III})$ and hematite. Geochim. Cosmochim. Acta 66, 2995-3015.

Strauss R., Brummer G. W. and Barrow N. J. (1997) Effects of crystallinity of goethite. 2. Rates of sorption and desorption of phosphate. Eur. J. Soil Sci. 48, 101-114.

Schwertmann U. and Murad E. (1983) Effect of $\mathrm{pH}$ on the formation of goethite and hematite from ferrihydrite. Clays Clay Miner. 4, 277-284.

Slomp C. P., Malschaert J. P. and Van Raaphorst W. (1998) The role of adsorption in sediment-water exchange of phosphate in North Sea continental margin sediments. Limnol. Oceanogr. 43, 832-846.

Thibault P. J., Rancourt D. G., Evans R. J. and Dutrizac J. E. (2009) Mineralogical conformation of a near-P:Fe $=1: 2$ limiting stoichiometric ratio in colloidal P-bearing ferrihydrite-like hydrous ferric oxide. Geochim. Cosmochim. Acta 73, 364-376.

Torrent J. and Barron V. (2000) Key role of phosphorus in the formation of the iron oxides in Mars soils? ICARUS 145, 645647.

Tudge A. P. (1960) A method of analysis of oxygen isotopes in orthophosphate and its use in measurement of paleotemperatures. Geochim. Cosmochim. Acta 18, 81-93.

Van Stempvoort D. R., Reardon E. J. and Fritz P. (1990) Fractionation of sulfur and oxygen isotopes in sulfate by soil sorption. Geochim. Cosmochim. Acta 54, 2817-2826.

Vennemann T. W., Fricke H. C., Blake R. E., O’Neil J. R. and Colman A. (2002) Oxygen isotope analysis of phosphates: a comparison of techniques for analysis of $\mathrm{Ag}_{3} \mathrm{PO}_{4}$. Chem. Geol. 185, 321-336.

Wheat C. G., Feely R. A. and Motl M. J. (1996) Phosphate removal by oceanic hydrothermal process: an update of the phosphorous budget in the oceans. Geochim. Cosmochim. Acta 60, 3593-3608.

Willett I. R., Chartres C. J. and Nguyen T. T. (1988) Migration of phosphate into aggregated particles of ferrihydrite. J. Soil Sci. 39, 275-282.

Associate editor: Timothy W. Lyons 